\title{
Guidelinitis: \\ A new syndrome?
}

\author{
B Lynn Johnston MD FRCPC ${ }^{1}$, John M Conly MD FRCPC ${ }^{2}$
}

$\mathrm{T}$ he September/October 2000 issues of The Canadian Journal of Infectious Diseases (1) and the Canadian Respiratory Journal (2), as well as the February issue of Clinical Infectious Diseases (3), published updated guidelines for the management of community-acquired pneumonia. Previous Canadian guidelines were published in 1993 (4). A MEDLINE search for clinical practice guidelines for community-acquired pneumonia reveals 10 additional citations from such groups as the Institute for Clinical Systems Improvement (5), the Infectious Diseases Society of America (6-8), the European Respiratory Society (9), the South African Pulmonology Society and the Antibiotic Study Group of South Africa (10), the Italian Society of Pneumonology, the Italian Society of Respiratory Medicine, the Italian Society of Chemotherapy (11), the American Thoracic Society (12), and the British Thoracic Society $(13,14)$. Where has all this interest in guidelines come from? How can there be so many guidelines for a single topic? More important, how do we choose among the embarrassingly different array of guidelines for the same infection?

Guidelines for clinical management are not new. However, the plethora of guidelines and the interest in their development has been a phenomenon largely of the past decade. Several authors have acknowledged the varied driving forces behind this interest in clinical practice guidelines (15-21). One is the reality that the passive diffusion of scientific advances to physicians and the incorporation of those advances into their practice often meet with poor success. This is made even more problematic by the enormous amount and complexity of information that is made available to physicians (and their patients) on an ongoing basis. Assuming physicians had time to review the latest literature, not all would have the skills to evaluate the various options critically. It is well recognized that there are variations in clinical practice, both within communities and between communities. While variations in practice do not necessarily and invariably mean poor practice by some, they certainly do raise the question and attendant concern about whether there is delivery of appropriate care and the best use of resources. There is no doubt that a major force driving guideline development has been concern over escalating health care costs and a desire to contain them, obtaining the most benefit for the least dollars. Finally, there is pressure for greater public accountability and increased public involvement in decision-making. Guidelines are one tool for making care more consistent and closing the gap between what clinicians do and what the evidence supports (15). Cost, quality and unnecessary care are all at issue (19). The premise is that guidelines will facilitate more consistently effective and efficient medical care, and ultimately lead to improved outcomes for patients (22). Given the different reasons for guidelines, it is not surprising that they come from a number of different sources: local groups of physicians, specialty and subspecialty societies, governmental and nongovernmental organizations, and third party payers, not infrequently with pharmaceutical industry financial support.

The American guidelines initiative gained a foothold in late 1989 with the creation of the Agency for Health Care Policy and Research (AHCPR). As part of its broad responsibilities for supporting research, data development and other activities to enhance the quality, appropriateness and effectiveness of health care services, one of their functions was to develop, disseminate and evaluate practice guidelines (23). At its request, the Institute of Medicine (IOM), Washington,

\footnotetext{
${ }^{1}$ Queen Elizabeth II Health Sciences Centre and Dalhousie University, Halifax, Nova Scotia; ${ }^{2}$ University Health Network, University of Toronto, Toronto, Ontario

Correspondence and reprints: Dr Lynn Johnston, Room 5014 ACC, Queen Elizabeth II Health Sciences Centre, 1278 Tower Road, Halifax, Nova Scotia B3H 2Y9. Telephone 902-473-8477, fax 902-473-7394, e-mail ljohnsto@is.dal.ca and Dr John Conly, Department of Medicine, Division of Infectious Diseases, Suite 13-118 Norman Urquhart Wing, Toronto General Hospital, University Health Network, 200 Elizabeth Street, Toronto, Ontario M5G 2C4. Telephone 416-340-4858, fax 416-340-5047, e-mail john.conly@uhn.on.ca
} 
TABLE 1

Attributes of good clinical practice guidelines

\begin{tabular}{|c|c|}
\hline Attribute & Discussion \\
\hline Validity & $\begin{array}{l}\text { The most critical attribute. If followed, a } \\
\text { valid practice guideline will lead to the } \\
\text { health and cost outcomes projected for it } \\
\text { Will consider items outlined in Table } 2\end{array}$ \\
\hline $\begin{array}{l}\text { Reliability and } \\
\text { reproducibility }\end{array}$ & $\begin{array}{l}\text { Given the same evidence and methods } \\
\text { for guideline development, another set of } \\
\text { experts would produce essentially the } \\
\text { same statements and given the same } \\
\text { clinical circumstances, guidelines } \\
\text { are interpreted and applied consistently }\end{array}$ \\
\hline Clinical applicability & $\begin{array}{l}\text { As inclusive of defined populations as } \\
\text { evidence and expert judgment permit, } \\
\text { and explicitly stating the populations to } \\
\text { which they apply }\end{array}$ \\
\hline Clinical flexibility & $\begin{array}{l}\text { The specifically known or generally } \\
\text { expected exceptions identified }\end{array}$ \\
\hline Clarity & $\begin{array}{l}\text { Unambiguous language used; terms } \\
\text { defined precisely; logical and easy-to- } \\
\text { follow presentation use }\end{array}$ \\
\hline Multidisciplinary process & $\begin{array}{l}\text { Includes participation by representatives of } \\
\text { key affected groups through: serving on } \\
\text { developing panels, providing evidence, } \\
\text { reviewing draft guidelines }\end{array}$ \\
\hline Scheduled review & $\begin{array}{l}\text { Include statements about when the } \\
\text { guidelines should be reviewed to } \\
\text { determine whether revisions are } \\
\text { warranted }\end{array}$ \\
\hline Documentation & $\begin{array}{l}\text { Procedures followed, participants, } \\
\text { evidence used, assumptions and rationales } \\
\text { accepted, and analytic methods used }\end{array}$ \\
\hline
\end{tabular}

Adapted from reference 33

DC appointed a committee to advise AHCPR on how to approach this. The result was two publications that provided guidance on definitions and key attributes of guidelines as well as their development, implementation and use $(23,24)$. In Canada, the Canadian Medical Association established a quality of care committee to spearhead a national initiative on quality of care in 1990 (25). From this evolved the National Partnership for Quality in Health. Initial partners were the Association of Canadian Medical Colleges, College of Family Physicians of Canada, Federation of Medical Licensing Authorities of Canada, Royal College of Physicians and Surgeons of Canada, and the Canadian Medical Association. They were later joined by the Canadian Association of Interns and Residents, and Canadian Council on Health Facilities Accreditation. To support the clinical practice guidelines process, a series of articles on their development and use was published in the Canadian Medical Association Journal in 1992 and 1993 (18,19,21,22). Elsewhere, guidelines have either been in existence for a number of years (United Kingdom, Australia) or have recently been developed (the Netherlands, Finland, Sweden, France, Germany, Italy, Spain and New Zealand) (15).

What exactly are clinical practice guidelines? The IOM has defined them as systematically developed statements to assist practitioner and patient decisions about appropriate health care for specific clinical circumstances (23). It believes that such guidelines can serve as useful tools for many desirable changes, from improving the quality of clinical care (and its measurement) to reducing the financial cost of inappropriate, unnecessary or dangerous care (24). Clinical practice guidelines gather, evaluate and combine evidence, and attempt to address all the issues relevant to a clinical decision and all the values that may sway a clinical recommendation (26). Guidelines may find several roles: quality assurance, enhancement of access to care, cost control, patient empowerment, professional autonomy and medical liability, and physician education (18).

Woolf et al (15) identified a number of potential benefits to patients, health care professionals and the health care system from the application of clinical practice guidelines. For patients, the potential benefits include improved outcomes through promotion of effective interventions, avoidance of ineffective ones, consistency of care and education. Clinical guidelines may indirectly benefit patients by influencing public policy, resource distribution and the research agenda toward initiatives that improve health outcomes. The potential benefits for health care professionals are the improved quality of decisions deriving from recommendations based on a critical review of the evidence, support of quality improvement activities and identifying gaps in knowledge to be pursued through research. These benefits to patients and health care workers will, in turn, benefit the health care system.

Like many things, however, guidelines may be a two-edged sword and should not be viewed as the panacea for a troubled health care system. They have their limitations and potential harms $(15,27,28)$. For many health problems, the scientific evidence supporting various treatment options may be limited, misleading or even nonexistent. It is often necessary to consider various types of evidence, ranging from large, randomized controlled trials to expert opinion. When the evidence is incomplete, there will be legitimate variation in the inferences drawn from it (19). Recommendations based solely on clinical judgment and experience are more likely to be susceptible to bias and self-interest $(26,28)$. Even where good evidence exists, practitioners may interpret it differently, perhaps related to their specialty or subspecialty biases. Additionally, specialist bodies, third party payers or other interest groups may have a vested interest in certain management options (19). Individual biases may be better balanced in multidisciplinary groups, and such balance may produce more valid guidelines $(26,28)$. In view of the differing levels of evidence, methods for developing guidelines and the recommendations coming from them may also vary widely, even in a single area, if the developers draw on different studies and have different strategies for using and ranking expert opinion. A quality-of-evidence scale can be included with the guidance to rate different categories of evidence and the methods that were used, as well as a strength of evidence scale (26). Guidelines may not reflect the values placed on 
different outcomes by patients, nor actual health care priorities and needs. Additionally, patient needs may not be the only priority considered in making recommendations. As a result, doctors may be faced with a number of guidelines on a single topic, potentially with conflicting and/or faulty recommendations. In the extreme, this could result in guidelines that are wrong or at least wrong for the individual patient. It is important to remember that guideline recommendations have to be evaluated critically by the user and may need to be set aside by individual patient considerations and choices (19). Apart from the potential for being incorrect, conflicting recommendations from (and within) different groups can lead to irritation, confusion and mistrust of guidelines in general. Even in the absence of conflict, multiple guidelines raise important questions about duplication of effort and wasted resources.

The potential harm of clinical practice guidelines to health care professionals is if guidelines provided inaccurate information and advice leading to ineffective, harmful or wasteful interventions; were conflicting; were difficult or time consuming to use; were used to judge an individual physician's practice unfairly; or discouraged the research agenda by declaring efficacy, or lack thereof, of an intervention (15). Guidelines have the potential to increase utilization (which may be justified and result in worthwhile and beneficial outcomes), divert resources to other areas, and if wrong, compromise efficiency and waste resources.

This is not to say that the clinical practice guideline effort should be left behind and move exclusively to other initiatives to improve the quality of care. Rather, increased effort should be put into developing guidelines according to standardized methodologies and into their evaluation. Agencies and groups taking responsibility for guideline development should have an overall plan that includes setting priorities and design, testing, implementation, evaluation and revision. An explicit description of the methodology used to develop the guideline is crucial for the user to assess its value, and understand why and where it may differ from other guidelines on that topic (29). Guidelines should receive external review to insure content validity, clarity and applicability, with reviewers covering three areas: content expertise, systematic reviews and/or guideline development and use (28). Practice guidelines deserve the same degree of rigorous consideration that the evidence on which they are based received (19).

If practice guidelines are to facilitate high quality care, they must be developed and prescribed carefully (22). The IOM has identified eight attributes of practice guidelines (Table 1), all linked by credibility (with practitioners, patients, payers and policy makers) and accountability (23). The key to accountability is disclosure and meticulous documentation of the procedures, participants, evidence, assumptions, rationales and analytic methods used in forming the guideline. If these are not included, the reader may be suspicious that the steps were not performed systematically, and then he or she is left unable to evaluate the guidelines and their suitability for his or her practice $(26,29,30)$. The most
TABLE 2

Format for structured abstracts of clinical practice guidelines

\begin{tabular}{|c|c|}
\hline Element & Discussion \\
\hline Objective & $\begin{array}{l}\text { - Identify the health problem and } \\
\text { targeted patients, physicians and } \\
\text { settings } \\
\text { - May specify why a guideline is } \\
\text { needed and how it should be used }\end{array}$ \\
\hline Options & $\begin{array}{l}\text { - Indicate the main management } \\
\text { options considered }\end{array}$ \\
\hline Outcomes & $\begin{array}{l}\text { - State those outcomes considered in } \\
\text { comparing different options }\end{array}$ \\
\hline Evidence & $\begin{array}{l}\text { - State what evidence was used, how was it } \\
\text { gathered and how was it dealt with } \\
\text { - Should specify the publication dates } \\
\text { of most recent evidence gathered }\end{array}$ \\
\hline Values & $\begin{array}{l}\text { - State how were the values assigned and } \\
\text { who participated in the process }\end{array}$ \\
\hline Benefits, harms, costs & $\begin{array}{l}\text { - State the type and magnitude, preferably } \\
\text { in absolute terms, expected from } \\
\text { the application of the guideline }\end{array}$ \\
\hline Recommendations & - Be brief, specific and clear \\
\hline Validation & $\begin{array}{l}\text { - Indicate external reviewers, if the } \\
\text { guideline was tested, explain conflict } \\
\text { or agreement with other guidelines }\end{array}$ \\
\hline Sponsors & $\begin{array}{l}\text { - State who developed, funded and/or } \\
\text { endorsed the guideline }\end{array}$ \\
\hline
\end{tabular}

Adapted from reference 27

important attribute is validity. Elements needed to allow the determination of validity are a description of the options and outcomes considered, the literature reviewed, evidence for the outcomes, estimates of the effect of the guideline (benefits, harms and costs) on the outcomes, methods used to make the estimates and patient preferences for the outcomes $(26,29,31)$. Hayward et al (27) have recommended an abstract format (Table 2) for authors to use with their guidelines to assist the user in judging their validity. More consistent reporting of guideline development methods is needed to make the guideline literature more accessible to and useful for prospective guideline users (32). Explanations should be provided for any conflict or inconsistency between the guideline in question and those developed by others. This documentation may help the user to judge where differences are arising: the interpretation of the evidence, rationale for the guideline, targets of the guideline, objectives of the guideline, value judgments, or care in developing the guidelines $(22,23,31)$.

What do physicians think about clinical practice guidelines? It seems to be a lukewarm relationship at best. The results of a survey of 2600 members of the American College of Physicians were published in 1994 (20). The survey's purpose was to assess familiarity with and confidence in clinical practice guidelines. There was a $60 \%$ response rate. The following views were held: $65 \%$ thought that guidelines would improve the quality of care, $43 \%$ believed that they would increase health care costs, $68 \%$ felt that they would be used to discipline physicians, $34 \%$ thought that they would make 


\section{TABLE 3}

Canadian Infectious Disease Society members attitudes towards clinical practice guidelines (CPGs)

\begin{tabular}{|c|c|c|c|c|c|}
\hline Attitude & $\begin{array}{l}\text { Strongly } \\
\text { agree (\%) }\end{array}$ & $\begin{array}{l}\text { Somewhat } \\
\text { agree (\%) }\end{array}$ & $\begin{array}{l}\text { Strongly } \\
\text { neutral (\%) }\end{array}$ & $\begin{array}{l}\text { Somewhat } \\
\text { disagree (\%) }\end{array}$ & $\begin{array}{l}\text { Strongly } \\
\text { disagree }(\%)\end{array}$ \\
\hline $\begin{array}{l}\text { 1. CPGs are a solution to runaway medical } \\
\text { costs and poor quality of care }\end{array}$ & 0 & 73 & 5 & 19 & 3 \\
\hline $\begin{array}{l}\text { 2. Royal College recertification should } \\
\text { require knowledge of CPGs }\end{array}$ & 24 & 40 & 12 & 12 & 12 \\
\hline $\begin{array}{l}\text { 3. Relicensing and recredentialling should } \\
\text { be based on compliance with CPGs }\end{array}$ & 3 & 49 & 3 & 31 & 14 \\
\hline $\begin{array}{l}\text { 5. CPGs rooted in consensus or opinion } \\
\text { only have no role }\end{array}$ & 19 & 28 & 13 & 34 & 6 \\
\hline $\begin{array}{l}\text { 6. I am a committed proponent and user of } \\
\text { CPGs in my practice }\end{array}$ & 13 & 55 & 16 & 11 & 5 \\
\hline
\end{tabular}

practice less satisfying, and $64 \%$ and $67 \%$, respectively, believed that they were good educational tools and convenient sources of advice. Of interest, and perhaps reflecting an inherent suspicion of third party payers, was the finding that $6 \%$ and $82 \%$, respectively, gave high ratings to the same guidelines for diagnostic testing developed by Blue Cross/Blue Shield, an insurance company, and the American College of Physicians. Also not surprising was that subspecialists had the greatest confidence in and more familiarity with guidelines developed by their own subspecialty organizations. Finally, while most respondents reported that clinical practice guidelines had some effect on their decisionmaking, fewer than $20 \%$ rated it as major.

Members of the Canadian Infectious Disease Society (CIDS) in attendance at CIDS Day 1999 offered their views on clinical practice guidelines (Table 3) (personal communication, L Johnston). Most (40\%) felt that guidelines should be developed by national medical and subspecialty societies while others believed that they should be developed by individual facilities to meet local needs (24\%), an independent institution with expertise in guideline development (24\%) or government-funded multidisciplinary groups (12\%).

In the end, clinical practice guidelines are only one option for improving the quality of care (32). Woolf et al (15) has suggested that they make sense when practitioners are unclear about appropriate practice and when scientific evidence can provide an answer. When clinicians already know the information, the task needs to shift to identify ways to change behaviour. Implementation is as critical as developing the guideline (32). Factors influencing acceptability include representation of the user group(s) on the developing body and perceived ownership of the opinion (19). This underlines the importance of one of the attributes noted by the IOM - a multidisciplinary process. We, as clinicians, must critically evaluate clinical practice guidelines before applying them to our patients. As members of a subspecialty society, we should support the development, implementation and evaluation of practice guidelines that fulfill the attributes outlined by the IOM and address high priority health care needs.

\section{REFERENCES}

1. Mandell LA, Marrie TJ, Grossman RF, et al. Summary of Canadian guidelines for the initial management of communityacquired pneumonia: an evidence-based update by the Canadian Infectious Disease Society and the Canadian Thoracic Society. Can J Infect Dis 2000;11:237-248.

2. Mandell LA, Marrie TJ, Grossman RF, et al. Summary of Canadian guidelines for the initial management of communityacquired pneumonia: an evidence-based update by the Canadian Infectious Disease Society and the Canadian Thoracic Society. Can Respir J 2000;7:371-82.

3. Mandell LA, Marrie TJ, Grossman RF, Chow AW, Hyland RH. Canadian guidelines for the initial management of communityacquired pneumonia: an evidence-based update by the Canadian Infectious Disease Society and the Canadian Thoracic Society. Clin Infect Dis 2000;31:383-421.

4. Mandell LA, Neiderman MS, and the Canadian Community Acquired Pneumonia Consensus Conference Group. Antimicrobial treatment of community-acquired pneumonia in adults: a conference report. Can J Infect Dis 1993;4:25-8.

5. Institute for Clinical Systems Improvement. Communityacquired pneumonia. Outpatient treatment of patients 16 years and older. Postgrad Med 2000;107:246-53.

6. Bernstein JM. Treatment of community-acquired pneumonia IDSA guidelines. Chest 1999;115:9S-13S.

7. Bartlett JG, Breiman RF, Mandell LA, File TM Jr. Communityacquired pneumonia in adults: guidelines for management. Clin Infect Dis 1998;26:811-38.

8. Chow AW, Hall CB, Klein JO, Kammer RB, Meyer RD, Remington JS. Evaluation of new anti-infective drugs for the treatment of respiratory tract infections. Clin Infect Dis 1992;15:S62-88.

9. European Respiratory Society. ERS Task Force Report. Guidelines for management of adult community-acquired lower respiratory tract infections. Eur Respir J 1998;11:986-91.

10. Working groups of the South African Pulmonology Society and the Antibiotic Study Group of South Africa. Management of community-acquired pneumonia in adults. S Afr Med J 1996;86:1152-63.

11. Gialdroni Grassi G, Bianchi L. Guidelines for the management of community-acquired pneumonia in adults. Monaldi Arch Chest Dis 1995;50:21-7.

12. Niederman MS, Bass JB Jr, Campbell GD, et al. Guidelines for the initial management of adults with community-acquired pneumonia: diagnosis, assessment of severity, and initial antimicrobial therapy. Am Rev Respir Dis 1993; 148:1418-26.

13. The British Thoracic Society. Guidelines for the management of community-acquired pneumonia in adults admitted to hospital. Br J Hosp Med 1993;49:346-50.

14. Harrison BD, Farr BM, Connolly CK, Macfarlane JT, Selkon JB, Bartlett CL. The hospital management of community-acquired pneumonia. J R Coll Physicians Lond 
$1987 ; 2: 267-9$

15. Woolf SH, Grol R, Hutchinson A, Eccles M, Grimshaw J. Potential benefits, limitations, and harms of clinical guidelines. BMJ 1999;318:527-30.

16. Flanagin A, Lundberg GA. Clinical decision making: promoting the jump from theory to practice. JAMA 1990;263:279-80.

17. Eddy DM. The challenge. JAMA 1990;263:287-90.

18. Battista RN, Hodge MJ. Clinical practice guidelines: between science and art. Can Med Assoc J 1993;148:385-9.

19. Health Services Research Group. Standards, guidelines and clinical policies. Can Med Assoc J 1992;146:833-7.

20. Tunis SR, Hayward RSA, Wilson MC, et al. Internists' attitudes about clinical practice guidelines. Ann Intern Med 1994;120:956-63.

21. Oxman AD. Coordination of guidelines development. Can Med Assoc J 1993;148:1285-8.

22. Hayward RSA, Laupacis A. Initiating, conducting and maintaining guidelines development programs. Can Med Assoc J 1993;148:507-12.

23. Field MJ, Lohr KN, eds. Clinical Practice Guidelines. Directions for a New Program. Washington, DC: National Academic Press, 1990.

24. Field MJ, Lohr KN, eds. Clinical Practice Guidelines. From Development to Use. Washington, DC: National Academic Press, 1992.

25. Carter A. Background to the "Guidelines for Guidelines" series. Can Med Assoc J 1993;148:383.
26. Hayward RSA, Wilson MC, Tunis SR, Bass EB, Guyatt G, for the Evidence-Based Medicine Working Group. Users' guide to the medical literature, VIII: how to use clinical practice guidelines, A. Are the recommendations valid? JAMA 1995;274:570-4.

27. Hayward RSA, Tunis SR, Wilson MC, Bass EB, Rubin HR, Haynes RB. More informative abstracts of articles describing clinical practice guidelines. Ann Intern Med 1993;118:731-7.

28. Shekelle PG, Woolf SH, Eccles M, Grimshaw J. Developing guidelines. BMJ 1999;318:593-6.

29. Evidence-Base Care Resource Group. Evidence-based care: 2 . Setting guidelines: how should we manage this problem. Can Med Assoc J 1994;150:1417-23.

30. Wilson MC, Hayward RSA, Tunis SR, Bass EB, Guyatt G, for the Evidence-Based Medicine Working Group. Users' guides to the medical literature, VIII. how to use clinical practice guidelines, B. What are the recommendations and will they help you in caring for your patients? JAMA 1995;274:1630-2.

31. Eddy DM. Resolving conflicts in practice policies. JAMA 1990;264:389-91.

32. Feder G, Eccles M, Grol R, Griffiths C, Grimshaw J. Using clinical guidelines. BMJ 1999;318:728-30.
HIV and AIDS Testing, Screening, and Confidentiality (1999). Rebecca Bennett and Charles A Erin, eds. Oxford University Press Canadian Branch, 70 Wynford Drive, Don Mills, Ontario M3C $1 \mathrm{J9}$. ISBN 0-19-823801-0; 412 pages; $\$ 45.00$

In the modern world of health care, it seems that society is often many years behind in dealing with the bioethical dilemmas that arise as a result of new technologies, treatments and diseases or illnesses. Even though the human immunodeficiency virus (HIV) has been with us for over two decades, the ethics of the pandemic continue to pose interesting challenges to everyone involved in the care of individuals infected with and affected by this retrovirus.

HIV and AIDS Testing, Screening, and Confidentiality is a timely and important book. It examines the issues of HIV testing, screening and confidentiality, primarily from the European perspective. It also includes references to and cases from the past, but with a view to the future. There are several authors, including ethicists, philosophers, physicians, lawyers, researchers and psychologists, who contribute to the in-depth views represented in the book. While there is no Canadian content, one chapter examines the subject from a critical, legal, American perspective. The cas- es and arguments used to illustrate subjects such as 'Individual responsibility for health' and 'Can health care workers care for their patients and be third-party interests?' are presented clearly and with passion. Some questions are answered, and others are raised.

A book written by the Pan American Health Organization in 1992 titled Ethics and Law in the Study of AIDS by Fuenzalida-Puelma et al addresses similar issues; however, it does so from a Pan American perspective.

Although HIV and AIDS Testing, Screening, and Confidentiality is well referenced, one criticism is that many of the references are dated before 1995. However, the writing is consistent, and the editors have done a good job of keeping the authors on track with their respective subject matters. There are no pictures or graphic illustrations.

Obviously, HIV and AIDS Testing, Screening, and Confidentiality will be of interest to those involved with bioethics, but it is also suitable reading and a resource for philosophers, lawyers, social workers, legislators or policy makers, HIV advocates, researchers, health care trainees, and health care professionals. It would be a valuable reference book for libraries.

Anne Russell RN BN Health Sciences Centre Winnipeg, Manitoba 


\section{ERRATA}

In Table 1 of the paper, "Guidelinitis: A new syndrome?" (Can J Infect Dis Vol 11[6]:299-303), reference 23 was identified as reference 33 . The error is regretted.

In the paper, "An algorithm for the management of acute bacterial cellulitis" (Can J Infect Dis Vol 11[Suppl D]:11D-14D), the dose of oral ciprofloxacin in Table 1 for cat bite is written as $100 \mathrm{mg}$ bid. It should be $500 \mathrm{mg}$ bid. The error is regretted. 


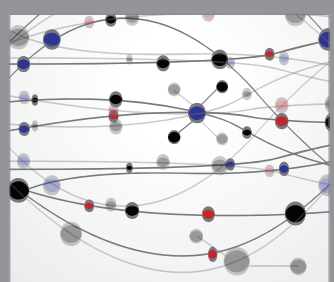

The Scientific World Journal
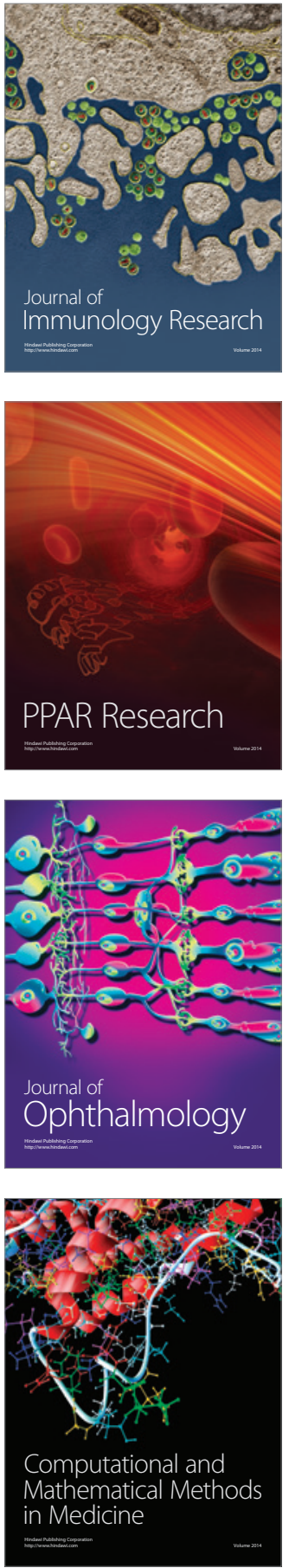

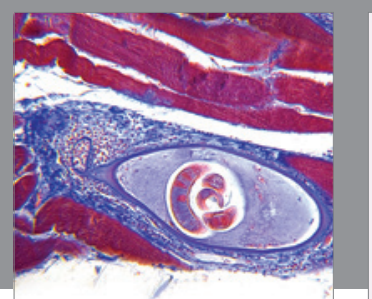

Gastroenterology Research and Practice

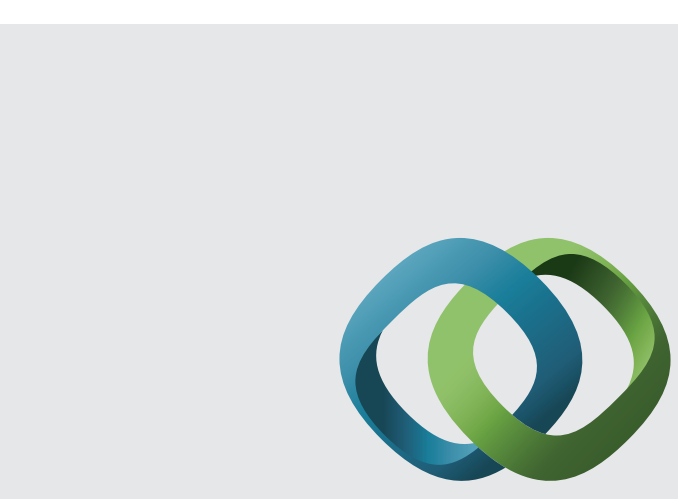

\section{Hindawi}

Submit your manuscripts at

http://www.hindawi.com
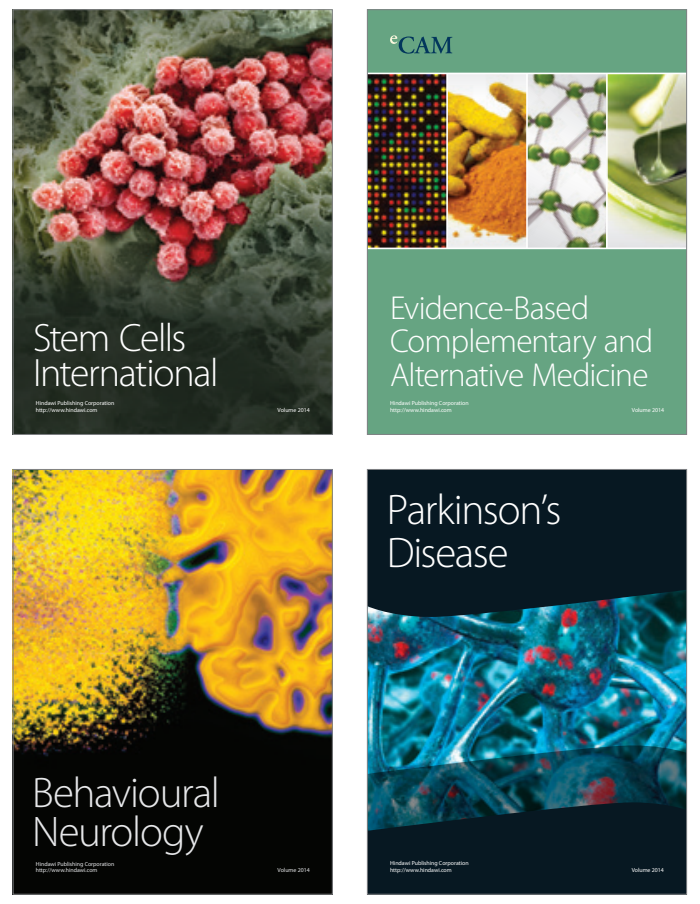
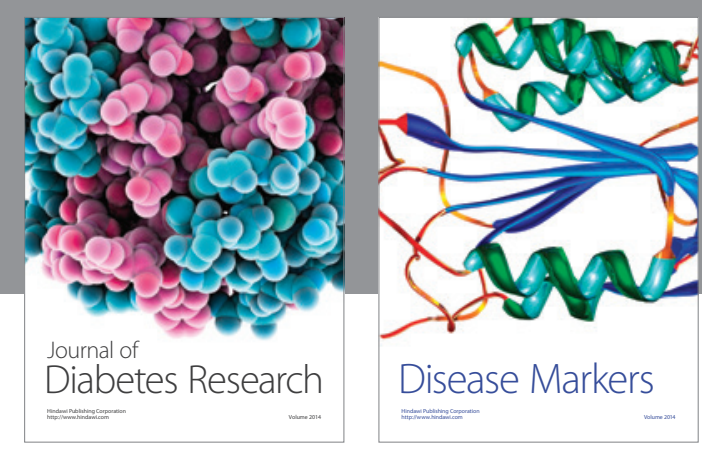

Disease Markers
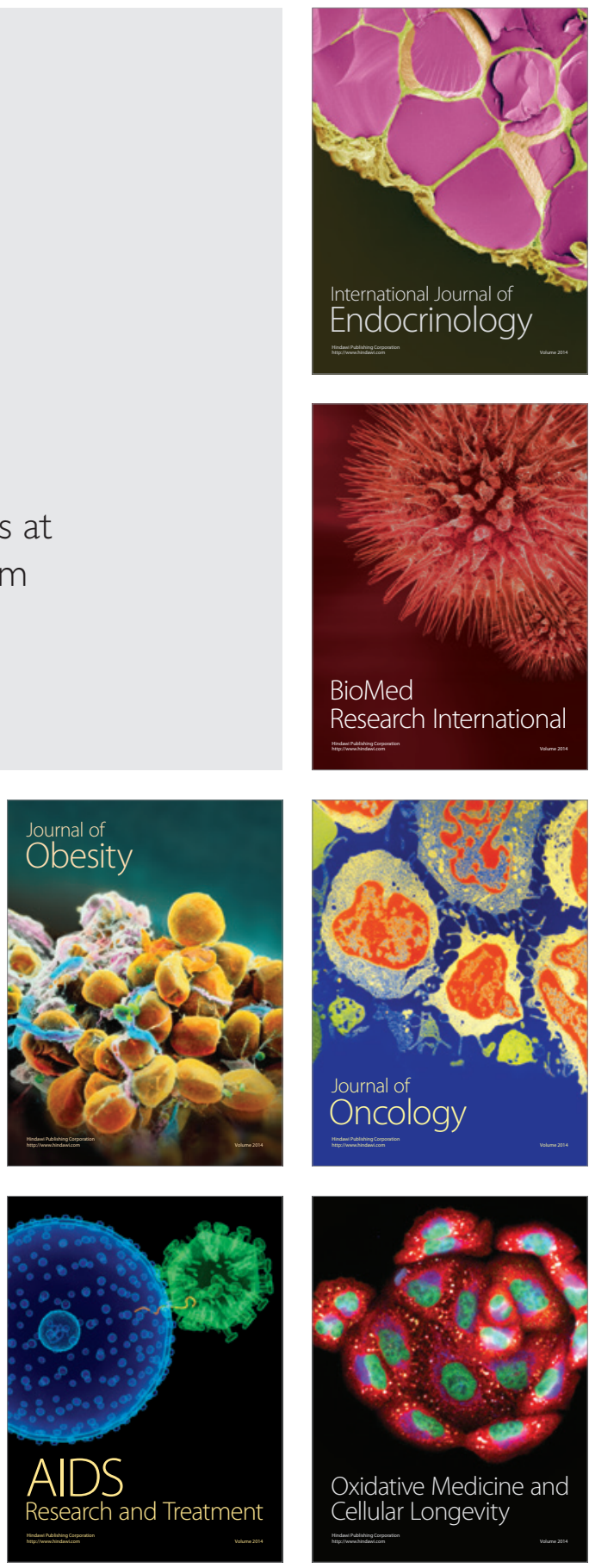